\title{
EL ABSENTISMO LABORAL EN ESPAÑA Y PROPUESTAS ANTIABSENTISMO DESDE EL PUNTO DE VISTA LEGAL*
}

\author{
TOMAS SALA Franco $*$
}

\section{El DOBle SIGNIFICADO LEGAL DEL ABSENTISMO LABORAL}

El absentismo laboral puede entenderse en un doble sentido:

a) Como "ausencias del trabajador al trabajo" comprensivas de las "faltas de puntualidad al trabajo" y de las "faltas de asistencia al trabajo", legalmente justificadas o no ("absentismo laboral" propiamente dicho).

b) Como "tiempo de trabajo perdido", esto es, el trabajador acude a su trabajo pero se dedica a tareas que no guardan relación con su puesto de trabajo (sobre todo, el derivado del uso y abuso de los teléfonos y ordenadores de la empresa por parte del trabajador con fines particulares durante la jornada de trabajo), que podrá estar igualmente justificado o no ("absentismo presencial").

\section{El tRATAMIENTO LEGAL DEL ABSENTISMO JUSTIFICADO: LOS SISTEMAS DE CONTROL} EMPRESARIAL DE LAS BAJAS POR INCAPACIDAD TEMPORAL DEL TRABAJADOR

Dejando a un lado los sistemas de control institucional de la incapacidad temporal Ilevado a cabo por los Servicios Públicos de Salud y por las Entidades Gestoras (INSS) y Colaboradoras (Mutuas patronales de accidentes de trabajo y enfermedades profesionales) de la Seguridad Social, los sistemas de control empresarial de las bajas por incapacidad temporal del trabajador reconocidos legalmente son la utilización de personal médico propio, el envío de "visitadores médicos" al domicilio del trabajador y el recurso a los detectives privados.

Durante la situación de incapacidad temporal, el empresario puede verificar el estado de la enfermedad/accidente alegado por el trabajador para justificar la incapacidad temporal (Art. 20.4 del ET) mediante la utilización de personal

\footnotetext{
* Colaboración recibida el 21 de abril y aprobada el 29 de abril de 2011.

${ }^{* *}$ Catedrático de Derecho del Trabajo y de la Seguridad social de la Universidad de Valencia. Estudio general. Correo elctrónico: tomas.sala-franco@uv.es.
} 
médico propio y la negativa del trabajador a este reconocimiento médico "podrá determinar la suspensión de los derechos económicos que pudieran existir a cargo del empresario por dichas situaciones". Lo cual significa:

$\left.1^{\circ}\right)$ Que únicamente se suspenderán las mejoras voluntarias empresariales al subsidio por incapacidad temporal que eventualmente tuviera contraídas el empresario por convenio colectivo o por pacto individual con el trabajador, pero no el subsidio que por ley asume el empresario en régimen de pago delegado a partir del día decimosexto de baja o en régimen de responsabilidad directa del cuarto al decimoquinto día de baja.

$2^{\circ}$ ) Que la negativa del trabajador a someterse al reconocimiento médico empresarial no constituye una desobediencia sancionable disciplinariamente por el empresario, protegiéndose en este caso el derecho a la intimidad del trabajador.

$\left.3^{\circ}\right)$ Que, en el caso de contradicción entre los informes médicos empresariales y los del facultativo del Servicio Público de Salud, prevalecen los de este último y el empresario ni podrá sancionar disciplinariamente al trabajador por transgresión de la buena fe contractual, ni podrá tampoco dejar de pagarle las mejoras voluntarias del subsidio, salvo que por convenio colectivo se hubiera condicionado la percepción de las mejoras al resultado positivo del control médico empresarial "ex Art. 20.4 del ET", si bien incluso esto resultaría discutible a la vista de los Arts. 115 y 1256 del Código Civil, por dejar al arbitrio de una de las partes pactantes el cumplimiento de la obligación pactada.

$4^{\circ}$ ) Que los únicos recursos que le quedan a la empresa serán: o bien acudir a la Inspección Sanitaria del Servicio Público de Salud correspondiente que, "en virtud de la información recibida de las empresas o de los servicios médicos de las mismas" puede llevar a cabo la verificación del estado de salud del trabajador durante la situación de incapacidad temporal, pudiendo confirmar la baja o emitir el alta médica con plenos efectos, o bien a la Inspección de Trabajo y Seguridad Social para denunciar aquellas actuaciones de sus trabajadores en situación de incapacidad temporal que entienda pueden ser consideradas como infracciones del orden social.

Por otra parte, las empresas pueden controlar la incapacidad temporal de sus trabajadores mediante el envío de "visitadores médicos" al domicilio del trabajador o recurriendo a los detectives privados, para que controlen la conducta del trabajador durante la situación de incapacidad temporal. En cualquiera de los caso, deberá respetarse el derecho a la intimidad de los trabajadores.

A mi juicio, la propuesta antiabsentismo adecuada en esta materia es la de reivindicar la absolutamente necesaria reforma del tratamiento integral de la incapacidad temporal. 
III. El tratamiento leGal DEL ABSENTISMO JUStifiCADO: lOS SISTEMAS DE CONTROL DE LOS PERMISOS, RETRIBUIDOS O NO, DEL TRABAJADOR

La ley establece dos tipos de mecanismos de control de las ausencias del trabajador por permisos, retribuidos o no, a los que tenga derecho:

a) De una parte, antes de su disfrute, el trabajador deberá preavisar al empresario de que va a hacer uso del correspondiente permiso, sin que, ciertamente, se concrete el mismo en el texto legal. De no preavisarse con una cierta antelación al empresario, podrá entenderse que el tiempo de permiso constituye una ausencia injustificada al trabajo, sancionable disciplinariamente, desde luego, siempre que ello sea posible en razón de la causa y de las circunstancias concurrentes.

b) De otra parte, la necesaria presentación al empresario, si éste la requiriera, de la correspondiente justificación, posterior a su disfrute, de que se ha utilizado precisamente para la finalidad legalmente prevista. Entendiéndose, en el caso de negativa del trabajador a presentar la justificación del permiso, que se trata de ausencias injustificadas al trabajo, si bien la jurisprudencia admite una cierta flexibilidad en cuanto a la justificación.

A mi juicio, la propuesta antiabsentismo en este punto iría en el sentido de la efectiva exigencia empresarial del preaviso y de la justificación.

IV. El tRATAMIENTO LeGAL DEL ABSENTISMO JUSTIFICADO:

LA REGULACIÓN DE LAS HORAS NO TRABAJADAS POR CULPA DEL EMPRESARIO

O POR FUERZA MAYOR

Para el caso de que el trabajador no pudiera realizar su trabajo "por causa imputable al empresario", el trabajador mantendrá su derecho al salario (Art. 30 del ET), configurándose la situación como un supuesto de "mora accipiendi" empresarial basado en la doctrina del riesgo empresarial.

Por su parte, las ausencias al trabajo "por causa de fuerza mayor" vienen configuradas en la ley como supuestos de suspensión del contrato, con pérdida del salario para el trabajador, si bien se exige para ello la previa autorización administrativa de la autoridad laboral competente (Arts. 45.1.i). 47.2 y 51.12 del ET).

En todo caso, no resulta fácil en la práctica distinguir claramente entre los supuestos de imputación empresarial del Art. 30 del ET y los atribuibles a la fuerza mayor y, por ello, causa de una suspensión del contrato. Así, por ejemplo, en los casos de retrasos de los trabajadores en la entrada al trabajo por causa de una huelga en los transportes o las horas perdidas por huelga en las empresas de suministros o de transportes o por lluvia en el sector de la construcción. 
A mi juicio, la propuesta antiabsentismo en este punto reside en el exacto conocimiento de los límites legales por parte de la empresa.

V. El CONTROL DEL ABSENTISMO INJUSTIFICADO: EL FICHAJE DE LOS TRABAJADORES

Y EL RÉGIMEN JURÍDICO SANCIONATORIO LEGAL Y JURISPRUDENCIAL DE LAS FALTAS DE PUNTUALIDAD Y ASISTENCIA AL TRABAJO

Por lo que se refiere al control del absentismo laboral injustificado, la exigencia empresarial de que los trabajadores fichen al entrar y al salir del trabajo constituye una práctica legal, conforme a lo dispuesto en el Art. 20.3 del ET, constituyendo la obligación de fichaje por parte de los trabajadores un sistema de control que, desde luego, no atenta a su "dignidad humana".

Por su parte, "las faltas repetidas e injustificadas de puntualidad o asistencia al trabajo" se consideran incumplimientos contractuales que, de ser graves y culpables, permitirán al empresario despedir disciplinariamente a un trabajador (Art. 54.2 a) del ET) o, en su caso, poder imponerle una sanción disciplinaria menor, de acuerdo con la tabla de faltas y sanciones laborales establecida en el convenio colectivo aplicable. A partir de este precepto, ha sido la jurisprudencia la que ha elaborado una doctrina interpretativa acerca de esta causa de sanción disciplinaria.

A mi juicio, la propuesta antiabsentismo adecuada en esta materia sería la de concretar convencionalmente el régimen disciplinario de las faltas de puntualidad y asistencia al trabajo.

\section{El CONTROL DEL ABSENTISMO PRESENCIAL: LA JURISPRUDENCIA ACERCA DEL ABUSO EN LA UTILIZACIÓN DE LOS ORDENADORES DE LA EMPRESA POR PARTE DE LOS TRABAJADORES}

En cuanto a la utilización de los ordenadores de la empresa por los trabajadores con fines particulares, cabe traer a colación, por su contenido altamente ilustrativo en este sentido, a las SS.TSJ de Galicia, de 30 de mayo de 2003 y de Cataluña, de 28 de enero de 2005.

De la lectura combinada de ambas Sentencias, es posible deducir que en la STSJ de Cataluña se establece una doctrina más benévola que en la STSJ de Galicia, por cuanto en esta última, en el caso de que no exista una expresa prohibición por parte de la empresa, el trabajador tiene derecho a hacer un uso moderado y no abusivo para asuntos ajenos al trabajo, mientras que en la STSJ de Galicia en el caso de inexistencia de prohibiciones o advertencias expresas por parte de la empresa, el trabajador no tiene derecho a hacer uso de los equipos informáticos de la empresa sin la expresa autorización de la misma.

En este punto mi propuesta antiabsentismo sería la de recomendar la regulación empresarial y/o convencional del tema. 
VII. EL CONTROL DEL ABSENTISMO PRESENCIAL: LA JURISPRUDENCIA ACERCA DEL ABUSO EN LA UTILIZACIÓN DE LOS TELÉFONOS DE LA EMPRESA POR PARTE DE LOS TRABAJADORES.

En relación con el uso de los teléfonos de la empresa con fines particulares por parte de los trabajadores, cabe traer a colación la STSJ de Galicia, de 30 de mayo de 2003.

Por lo que atañe a la valoración judicial de la gravedad de los hechos (la utilización del teléfono de la empresa para fines particulares durante un largo tiempo) en orden a justificar el despido disciplinario efectuado, considera la Sentencia que la utilización continuada y no autorizada del teléfono de la empresa por el trabajador fuera de la jornada laboral para realizar llamadas particulares "implica fraude, verdadera deslealtad y abuso de confianza en el desempeño laboral" y que la conducta pone de relieve "en sí misma un inequívoco contenido intrínseco de gravedad", no resultando en absoluto desproporcionada.

En este punto mi propuesta antiabsentismo sería también la de recomendar la regulación empresarial y/o convencional del tema.

\section{El CONTROl del abSENTISMO PRESENCIAL: LA JURISPRUDENCIA ACERCA DE LAS GRABACIONES VIDEOGRÁFICAS REALIZADAS EN EL}

CENTRO DE TRABAJO

A este respecto, cabe comentar la STSJ de Madrid de 6 de julio de 2004. La presente Sentencia viene referida al conflicto que se plantea frecuentemente entre el derecho a la intimidad del trabajador y el poder de dirección del empresario cuando éste, para controlar determinadas actuaciones de los trabajadores, decide colocar una cámara oculta en el centro de trabajo, planteándose la cuestión capital de la licitud de la conducta empresarial y, consiguientemente, del valor probatorio de las imágenes obtenidas.

En el presente caso, ante la sospecha de que se están produciendo irregularidades en los cobros de la mercancía por parte de determinados trabajadores, la empresa decide colocar una cámara oculta de grabación de imágenes en la zona donde se almacenan los alimentos y bebidas, sin conocimiento de los trabajadores salvo de los servicios de seguridad de la empresa, utilizando más tarde la grabación videográfica como prueba documental en el juicio por despido de los trabajadores implicados.

Por lo que se refiere a la licitud del control audiovisual efectuado por la empresa, la Sentencia aplicará la amplia y consolidada doctrina del Tribunal Constitucional existente acerca del equilibrio entre los derechos constitucionalmente reconocidos.

Así, partiendo de la aplicabilidad del derecho a la intimidad al ámbito de las relaciones laborales (por todas, STCO 98/2000), se afirma la reiterada doctrina 
de que el derecho a la intimidad, como cualquier otro derecho fundamental, no es absoluto, pudiendo ceder ante la presencia de otros intereses constitucionalmente relevantes, "siempre que el recorte que aquel haya de experimentar se revele como necesario para lograr el fin legítimo previsto, proporcionado para alcanzarlo y, en todo caso, respetuoso con el contenido esencial del derecho" (por todas, SS.TCO 57/1994 y 143/1994).

En el presente caso, la Sentencia considera que la medida adoptada por la empresa supera los tres juicios anteriores. Así:

a) El de idoneidad, por cuanto la cámara oculta fue colocada en el lugar idóneo para ejercer el control de las supuestas irregularidades de los trabajadores, esto es, en la zona de almacenaje de bebidas y alimentos para verificar exclusivamente las irregularidades sospechadas, las cuales se referían a un eventual desvío del género inventariado ante la falta de coincidencia de lo facturado.

b) El de necesidad, dado que la grabación servirá de prueba de las irregularidades sospechadas.

c) Y el de proporcionalidad, por cuanto la grabación se limita a la zona donde se sospechaba la existencia de irregularidades, esto es, "a la zona donde se almacenan los alimentos y bebidas, espacio discreto y reservado a la vista del público y donde, por lógico sentido, podían cometerse las presuntas irregularidades".

Concluye así la Sentencia en que "no cabe calificar la actuación empresarial de ilegítima intromisión en el derecho a la intimidad de los trabajadores" y en que "la filmación fue la indispensable y estrictamente necesaria para satisfacer el interés empresarial merecedor de tutela y protección".

Mi propuesta antiabsentismo en esta materia sería la de recomendar a la empresa el exacto conocimiento de los límites legales.

\section{El tratamiento legal ESPECífICO Del ABSENTISMO LabORAL: EL ART. 52 D) DEL ET.}

El Art. 52 d) del ET establece que el absentismo laboral injustificado, y aun el justificado en determinados casos, constituye una causa objetiva de extinción del contrato de trabajo, con un plazo de preaviso de 30 días (sustituible por el abono de los salarios correspondientes a los días de preaviso incumplidos) e indemnizada con 20 días de salario por año de servicio con el tope de 12 mensualidades (Art. 53 del ET).

En efecto, el Art. 52 d) del ET establece que "el contrato podrá extinguirse: ... d) Por faltas de asistencia al trabajo, aun justificadas pero intermitentes, que alcancen el $20 \%$ de las jornadas hábiles en dos meses consecutivos, o el $25 \%$ en cuatro meses discontinuos dentro de un período de doce meses, siempre que 
el índice de absentismo total de la plantilla del centro de trabajo supere el $5 \%$ en los mismos períodos de tiempo. No se computarán como faltas de asistencia, a los efectos del párrafo anterior, las ausencias debidas a huelga legal por el tiempo de duración de la misma, el ejercicio de actividades de representación legal de los trabajadores, accidente de trabajo, maternidad, riesgo durante el embarazo, enfermedades causadas por embarazo, parto o lactancia, licencias y vacaciones, enfermedad o accidente no laboral, cuando la baja haya sido acordada por los servicios sanitarios oficiales y tenga una duración de más de veinte días consecutivos, ni las motivadas por la situación física o psicológica derivada de violencia de género, acreditada por los servicios sociales de atención o servicios de salud, según proceda".

La literalidad de la norma legal plantea ciertamente problemas interpretativos importantes, resueltos contradictoriamente por la jurisprudencia y doctrina judicial. Entre otros más:

a) El de las ausencias computables o excluidas a estos efectos, materia ni mucho menos clara en el texto legal.

b) En cuanto al índice de absentismo, existen dudas acerca de si ha de darse en todos y cada uno de los meses o si basta con que se dé como media de los dos o cuatro meses.

c) Existen igualmente dudas acerca de si las exclusiones legales del cómputo del absentismo juegan solamente respecto del trabajador individual o también respecto del absentismo de la plantilla del centro.

d) Hay dudas también acerca de si estos índices de absentismo deben darse en los dos meses inmediatamente anteriores a la extinción o dentro del año anterior.

Mi propuesta en este punto sería la de recomendar la necesaria reforma del precepto legal, haciéndolo mucho más operativo para la finalidad pretendida, esto es, el control del absentismo laboral.

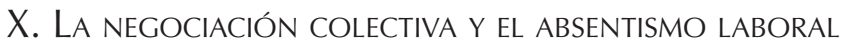

La negociación colectiva suele establecer una serie de cláusulas relacionadas con el absentismo laboral. Así:

- Se pactan "incentivos por reducción del absentismo laboral", en metálico o en especie, condicionando en ocasiones el derecho al complemento o mejora del subsidio por incapacidad temporal a la superación de un determinado porcentaje de absentismo en la empresa.

- Se establece la concreción de las faltas de puntualidad y de asistencia al trabajo a efectos sancionatorios.

- Se regulan las visitas al médico (con o sin comprobante posterior). 
- Se crean comisiones mixtas de control del absentismo.

- Se establece una regulación detallada del uso por los trabajadores de la telefonía o de los ordenadores de la empresa.

- Y, en general, se pactan medidas de mejora del clima laboral y de las condiciones de trabajo (aplicación de la ergonomía a los puestos de trabajo, una buena política de prevención de riesgos laborales, la existencia de una carrera profesional con posibilidades de ascensos o, al menos, de una promoción económica u horizontal, la flexibilidad de una cierta autogestión del tiempo de trabajo por el trabajador, el trabajo en equipo, la rotación de los puestos de trabajo, etc.) y las prácticas de "interesamiento" o de "fidelización" empresarial de los trabajadores.

No hay duda, en este sentido, de que cualquiera de estas medidas convencionales positivas puede hacer más por la reducción del absentismo laboral que las medidas de control o negativas. 